\title{
CONHECIMENTO ICTIOPARASITOLÓGICO TRADICIONAL DOS PESCADORES ARTESANAIS DO RIO JAGUARIPE, BAHIA, NORDESTE DO BRASIL
}

\author{
Traditional ictioparasitological knowledge of artisanal fishers from rio Jaguaripe, \\ Bahia, northeast of Brazil
}

\author{
Dalila Costa DANTAS ${ }^{1}$, Washington Luiz Gomes TAVECHIO ${ }^{1}$, Gislaine GUIDELLI ${ }^{1 *}$
}

${ }^{1}$ Núcleo de Sanidade Aquícola do Recôncavo (Sanar), Universidade Federal do Recôncavo da Bahia (UFRB), Centro de Ciências Agrárias, Ambientais e Biológicas (CCAAB). Rua Rui Barbosa, 710, Cruz das Almas, Bahia, Brasil. Contato:*gguidelli@ufrb.edu.br

\section{RESUMO}

Objetivou-se analisar o conhecimento tradicional sobre ocorrência de ictioparasitos e aspectos da relação parasito-hospedeiro em duas colônias de pescadores do Rio Jaguaripe, Bahia. A seleção dos participantes deu-se por amostragem bola de neve. Utilizou-se questionário semiestruturado juntamente à técnica de estímulo visual, usando-se imagens de peixes nativos e uma espécie controle. Vinte e sete pescadores foram selecionados, sendo 18 do município de Jaguaripe e 9 do município de Nazaré. Analisou-se os dados qualitativamente, por interpretação direta das respostas e comparação com publicações científicas e quantitativamente por frequências de respostas. Oito participantes de Nazaré e todos de Jaguaripe observaram a ocorrência de ictioparasitos, principalmente em peixes de valor comercial. Espécies de peixes indicadas como não parasitadas foram consideradas "peixes limpos", revelando repulsa, comum em relação a muitos invertebrados. Todos os participantes de Nazaré indicaram apenas a "carne" (musculatura somática) como sítio de infecção. Em Jaguaripe citaram boca $(88,8 \%)$, carne $(83,3 \%)$ e pele/escama $(44,4 \%)$. Trematoda, Nematoda e Crustacea foram os táxons reconhecidos, baseando-se na morfologia. A ocorrência e sítios de infecção indicados são corroborados por registros científicos. Participantes das duas comunidades relataram efeitos negativos dos parasitos aos peixes (perda de peso, hematofagia) e sazonalidade no parasitismo, denominando-a "variação na temporada". Circulação dos parasitos entre os componentes ambientais bióticos não fez parte do conhecimento tradicional, possivelmente por não ser um processo diretamente observável. Zoonoses foram negadas por todos os participantes, podendo representar risco à saúde.

Palavras-chave: Etnoecologia, Etnoparasitologia, Ictioparasitologia, Recôncavo da Bahia, Relação Parasito-Hospedeiro

\begin{abstract}
This study aimed to analyze the traditional knowledge about the occurrence of fish's parasites and parasite-host relationship aspects in two fishing communities on the Jaguaripe River, Bahia. The selection of participants took place through snowball sampling. A semi-structured questionnaire was used together with the visual stimulus technique using images of native fish and a control species. Twenty-seven fishers were selected, 18 from the fishers colony from Jaguaripe municipality and 9 from Nazaré. The data were analyzed qualitatively, by direct interpretation of the responses and comparison with scientific publications and quantitatively by presenting the response frequencies. Eight participants from Nazare and all from Jaguaripe observed the occurrence of fish's parasites, mainly in fish of commercial value. Fish species indicated as not parasitized were considered "clean fish", revealing disgust, common in relation to mane invertebrates. All participants in Nazaré indicated only "meat" (somatic musculature) as an infection site. In Jaguaripe mentioned mouth (88.8\%), meat $(83.3 \%)$ and skin/scale (44.4\%). Trematoda, Nematoda and Crustacea were the recognized taxa, based on morphology. The occurrence and indicated sites of infection are corroborated by scientific records.
\end{abstract}


Dantas et al. Conhecimento tradicional dos pescadores artesanais sobre os parasitos de peixes do rio Jaguaripe, Bahia, nordeste do Brasil. Ethnoscientia V.6, n.1, 2021. DOI: 10.22276/ethnoscientia.v6i1.339

Participants from both communities reported negative effects of parasites on fish (weight loss, hematophagy) and seasonality in parasitism, calling it "season variation." Circulation of parasites among biotic environmental components was not part of traditional knowledge, possibly because it is not a directly observable process. Zoonoses were denied by all participants, which may represent a health risk.

Keywords: Ethnoecology, Ethnoparasitology, Ichthyoparasitology, Recôncavo da Bahia, ParasiteHost Relationship

\section{INTRODUÇÃO}

Peixes são conhecidos por abrigarem grande diversidade de organismos parasitos, desde protistas e fungos a metazoários diversos (EIRAS et al., 2010). Este conhecimento é amplamente explorado na literatura científica e, para o público em geral, é mais difundido em canais de comunicação não científicos, a exemplo de notícias acerca da "doença do sushi" ou “da doença do peixe cru” (DEMARTINI, 2017; BEZERRA, 2020), o que pode ser explicado pelo aumento da popularidade da comida japonesa no mundo, destacado por Kamoey (2015).

Alguns parasitos de peixes são facilmente reconhecidos pelo seu aspecto desagradável, como no caso de larvas de trematódeos (Platyhelminthes, Trematoda) encistadas na musculatura dos peixes, na forma de protuberâncias, pontos negros ou amarelos (TAKEMOTO et al., 2004). Muitos, como nematoides e platelmintos, quando adultos colonizam peixes ou outros vertebrados piscívoros, tais como aves e mamíferos predadores aquáticos (SANTOS et al., 2013), usando a teia alimentar para cumprir as diferentes etapas do seu ciclo de vida e circulando por diferentes ambientes (MARCOGLIESE, 2002). Um grande conjunto de parasitos tem ainda importância na medicina humana, pois são agentes etiológicos de zoonoses (doenças transmitidas às pessoas pelos animais), sendo as mais importantes a anisakíase e a difilobotriose (PAVANELLI et al., 2015). Sendo assim, uma ampla gama de aspectos sobre o parasitismo em peixes pode ser explorada, entre eles a riqueza e diversidade taxonômica (LUQUE e POULIN, 2007), o impacto econômico (TAVARES-DIAS e MARTINS, 2017), na saúde humana (WILLIAMS et al., 2020; BUCHMANN e MEHRDANA, 2016) e a ecologia do parasitismo (POULIN, 2011).

O conhecimento tradicional sobre os parasitos de peixes, sua ecologia e seus efeitos na saúde dos peixes são pouco abordados na literatura científica. A etnoparasitologia é considerada uma ciência relativamente nova, tendo sido sugerida pela primeira vez por Gurgel-Gonçalves et al. (2007) como novo campo de estudos etnocientíficos. Por definição é a "parte da etnobiologia encarregada de estudar os conhecimentos tradicionais sobre a biologia dos parasitos e o modo como as populações humanas lidam com as doenças 
Dantas et al. Conhecimento tradicional dos pescadores artesanais sobre os parasitos de peixes do rio Jaguaripe, Bahia, nordeste do Brasil. Ethnoscientia V.6, n.1, 2021. DOI: 10.22276/ethnoscientia.v6i1.339

parasitárias" (GURGEL-GONÇALVES et al., 2007, p. 152). Esta ciência relaciona-se diretamente com a etnoecologia, uma vez que, por definição conforme Hecht et al. (2020), o parasitismo é considerado uma das relações ecológicas entre seres vivos. Relaciona-se ainda com a etnoictiologia, considerada de forma mais ampla como "a busca da compreensão do fenômeno da interação entre o Homem e os peixes, englobando aspectos tanto cognitivos quanto comportamentais" (MARQUES, 2012, p. 13-14). Todas essas ciências têm como objeto de estudo científico principal, o conhecimento ecológico tradicional (CET) (chamado ainda de conhecimento ecológico local - CEL). Refere-se a um sistema complexo e cumulativo de saberes, hábitos e crenças, provenientes da interação de uma população tradicional com seu ambiente e transmitido culturalmente (BERKES, 2003).

Estudos do CEL em comunidades de pescadores encontram-se bem desenvolvidos no Brasil, com várias pesquisas nas diferentes regiões (ARRUDA et al., 2018; BARROS, 2012; CARVALHO, 2002; GÜLLICH, 2019; HAVERROTH, 2018; LIMA et al., 2019; MESSIAS et al., 2006; MOURA e MARQUES, 2006; NUNES et al., 2011a; PIEVE et al., 2005; SILVANO e BEGOSSI, 2012). Estudos como os de Begossi et al. (2011 e 2012) e CostaNeto et al. (2019) têm um caráter aplicado referente ao CET, à media que propõem uma abordagem da gestão da pesca artesanal com a participação de pescadores, apontando sugestões para o manejo e criação de estratégias de proteção aos recursos naturais aquáticos. Este modelo integrativo do conhecimento tradicional e científico para fins conservacionistas é pressuposto da etnoconservação (DIEGUES, 2000). A comparação entre CEL e o conhecimento científico é comum, verificando-se convergências e o caráter complementar entre os dois tipos de conhecimento (PRADO e MURRIETA, 2015).

No que se refere ao CET dos parasitos, a maior parte dos estudos concentra-se na medicina humana, principalmente nas enfermidades causadas por organismos invertebrados e seu tratamento (SANTOS-LIMA et al., 2016; VASCO-DOS-SANTOS et al., 2018; SILVA et al., 2020). O campo da etnoveterinária, principalmente a investigação de recursos zooterapêuticos, também é abordado na literatura (ABO-EL-SOOUD, 2018; SOUTO et al., 2012).

Estudos publicados sobre o conhecimento tradicional dos parasitos de peixes são escassos e, muitas vezes, apresentados como dados complementares. Herbst e Hanazaki (2014), por exemplo, abordaram o CEL do ciclo de vida e migração de tainha (Mugil liza Valenciennes, 1836) no Sudeste do Brasil, levantando alguns dados sobre parasitos. Barboza e Pezzuti (2011), em análise da etnoictiologia em uma localidade no Pará, observaram o 
parasitismo como um dos fenômenos percebidos pelos pescadores locais. As publicações são uma forma de acessibilidade universal ao conhecimento socioambiental de comunidades tradicionais (TOMCHINSKY et al., 2019). Além disso, em regiões onde o conhecimento científico é limitado, a etnoecologia e a percepção popular são fontes de conhecimento sobre os processos operantes regionalmente (BARBOSA et al., 2017). Parasitos desempenham papéis influentes na estrutura e função dos ecossistemas, o que revela a necessidade de integrar a ecologia de doenças parasitárias e a ciência do ecossistema (PRESTON et al., 2016). Da mesma forma, o estudo do conhecimento ecológico tradicional de uma localidade torna-se mais sólido, à medida que aborda de forma efetiva a etnoparasitologia.

Este trabalho objetivou trazer à luz da ciência, o conhecimento tradicional etnoictioparasitológico de pescadores do Rio Jaguaripe, sobre a ocorrência de parasitos nos peixes e aspectos das interações parasito-hospedeiro. Com isto, pretendeu-se discutir e difundir este saber tradicional e, ao mesmo tempo, fornecer dados a serem somados à etnoecologia de comunidades de pescadores no Brasil.

\section{MATERIAL E MÉTODOS}

\section{1. Área de estudo}

O Rio Jaguaripe é um rio baiano, com a nascente localizada na Serra da Jibóia, município de Castro Alves e foz no canal de Itaparica, Baía de Todos os Santos, Bahia, Brasil (AUGUSTO, 1995).

A agricultura é a principal atividade no entorno do rio, causando impacto ambiental pelo uso de pesticidas, aterro do manguezal, efluentes domésticos e resíduos sólidos (ARAÚJO et al., 2018). As principais atividades pesqueiras são a mariscagem, a pesca artesanal e a extração de produtos do manguezal, havendo Colônias de Pescadores e Aquicultores na região (HATJE e ANDRADE, 2009).

A presente pesquisa foi desenvolvida em Colônias de Pescadores e Aquicultores em dois municípios baianos que, de acordo com IBGE (2017), são banhados pelo rio Jaguaripe (Figura 1): Nazaré e Jaguaripe. O espaço para a execução da pesquisa em Nazaré foi concentrado na sede da Colônia de Pescadores e Aquicultores Z09. Não houve a disponibilização da informação do número total de associados à Colônia. Em Jaguaripe, as reuniões e coleta de dados foram realizadas na Colônia de Pescadores e Aquicultores Z36. Segundo o presidente da associação, devido a oscilações cadastrais, não foi possível quantificar o total de membros integrantes. 
a b

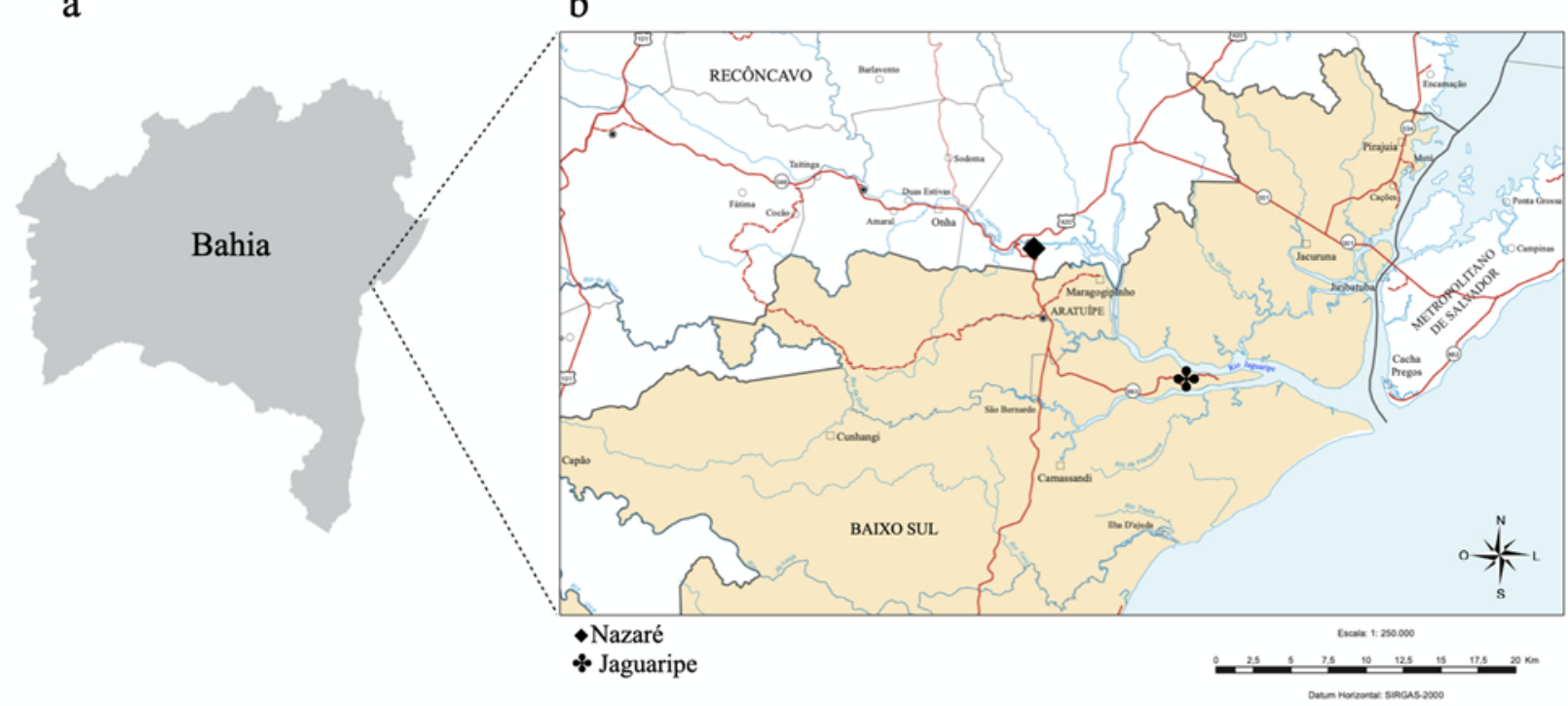

Figura 1: Localização dos municípios selecionados para o estudo. a) Estado da Bahia; b) Parte da região de abrangência da bacia do Rio Jaguaripe. Adaptado de

http://www.sei.ba.gov.br/site/geoambientais/mapas/pdf/regional/territorios_de_identidade/mapa_baixo_sul_1.pd f.

\subsection{Obtenção dos dados etnoictioparasitológicos}

\subsubsection{Aspectos éticos e legais da pesquisa}

O estudo foi previamente aprovado pelo Comitê de Ética em Pesquisa da Universidade Federal do Recôncavo da Bahia (CEP/UFRB), Número 2.104.193.

A metodologia para obtenção de autorização e consentimento para a pesquisa se deu de modo igual nas duas comunidades participantes. Foi realizada uma reunião com cada um dos responsáveis pelas Colônias, para apresentação da pesquisa e assinatura do Termo de Anuência. Posteriormente, foi realizada uma reunião com os pescadores de cada uma das comunidades e estes foram convidados a participar deste estudo. Aqueles que se mostraram disponíveis receberam o Termo de Consentimento Livre e Esclarecido (TCLE), específico para cada colônia e, após explicação detalhada do documento, este foi assinado e uma cópia foi entregue a cada um.

\subsubsection{Coleta de dados}

Além do convite direto durante a reunião, a seleção dos participantes foi feita através da metodologia "bola de neve" (BAILEY, 1982), onde um pescador reconhecidamente experiente recomenda outros. Prosseguiu-se com esse método até não haver mais indivíduos dispostos a colaborar. Os critérios usados para escolha dos participantes foram a maioridade, 
a dependência da pesca como principal fonte de subsistência ou a aposentadoria por este trabalho. Um total de 27 indivíduos participaram, sendo 9 de Nazaré (8 homens e 1 mulher, com idades entre 68 e 87 anos, informadas apenas por 3 participantes) e 18 de Jaguaripe (12 homens e 6 mulheres, média de idade de 40 anos e amplitude de 23 a 52, informação concedida por todos os participantes).

Os dados sobre os parasitos de peixes foram colhidos por meio de entrevistas semiestruturadas (VIERTLER, 2002). A utilização dessa técnica possibilitou a elaboração de um guia norteador, com o intuito de manter o foco central da pesquisa, mas garantiu que os entrevistados tivessem flexibilidade durante o depoimento, apresentando suas próprias convicções, enriquecendo o trabalho com informações adicionais (ALBUQUERQUE et al., 2014).

Utilizou-se pranchas com imagens coloridas de espécies de peixes como estímulos visuais durante as entrevistas, segundo metodologia de Medeiros et al. (2014). Foram apresentadas 14 pranchas coloridas das espécies nativas da região Anchoa spinifer (Valenciennes, 1848) - anchova; Achirus lineatus (Linnaeus, 1758) - linguado; Caranx sp. xaréu; Centropomus parallelus Poey, 1860 - robalo; Cynoscion sp. - pescada; Diapterus sp. carpeba; Narcine braziliensis (Olfers, 1831) - raia-elétrica; Ogcocephalus vespertilio (Linnaeus, 1758) - peixe-morcego; Hippocampus reidi Ginsburg, 1933 - cavalo-marinho; Hypanus guttatus (Bloch \& Schneider, 1801) - arraia; Hypostomus sp. - cascudo; Lutjanus sp. - vermelho; Mugil sp. - tainha e Sphoeroides spengleri (Bloch, 1785) - baiacu-pinima. Imagem de Atlantirivulus jurubatibensis (Costa, 2008) - rivulus, não ocorrente no rio, foi apresentada servindo como espécie controle para checagem da confiabilidade do conhecimento ecológico, partindo-se do pressuposto de que os participantes não a reconheceriam como espécie local (CLAUZET et al., 2007). Em Nazaré, além das pranchas, os pescadores participantes dispuseram-se a doar os seguintes espécimes de peixes para os relatos: Awaous tajacica (Lichtenstein, 1822) - gobi-do-rio; Geophagus sp. - acará; Gymnotus carpo Linnaeus, 1758 - tuvira; Hoplias malabaricus (Bloch, 1794) - traíra; Leporinus sp. piau. O mesmo ocorreu em Jaguaripe com as espécies Chaetodipterus faber (Broussonet, 1782) - paru; Cynoponticus savanna (Bancroft, 1831) - corongo.

As entrevistas foram realizadas por um único entrevistador, em horários escolhidos pelos indivíduos participantes e basearam-se nas seguintes questões, feitas durante a apresentação das imagens: (1) Você conhece algum destes peixes? Se sim, qual o nome dele? (2) Ele é comestivel ou é vendido? (3) Tem algum verme ou doença? (4) Se sim, o que esse 
verme causa no peixe? (5) Quando/em qual época o verme ocorre? (6) Sabe como o verme chega no peixe? (7) Esse verme causa doença nas pessoas?

O registro dos dados foi feito de forma escrita e por gravação de voz, devidamente autorizadas pelos participantes pela assinatura do TCLE. Os dados foram transcritos, categorizados e mantidos em banco de dados eletrônico no Núcleo de Sanidade Aquícola, da Universidade Federal do Recôncavo da Bahia.

\subsection{Análise dos dados}

A análise dos dados baseou-se no modelo de união das diversas competências individuais (HAYS, 1976), sendo consideradas para investigação e interpretação, todas as respostas obtidas. Foram feitas abordagens qualitativas e quantitativas, pois considerou-se que os dados qualitativos poderiam gerar categorizações quantitativas, com base no pressuposto de que os dois métodos são integrativos e não excludentes (VICTORA et al., 2000).

A metodologia principal foi a qualitativa e baseou-se em Marques (2002). Foram feitas análises e interpretações diretas das respostas dos participantes. Os dados científicos foram adquiridos de publicações em diferentes meios de comunicação e regiões do país, para serem comparados com o conhecimento tradicional dos pescadores pretendendo estabelecer relações entre os diferentes tipos de saberes (MARQUES, 2002).

As categorias usadas para a análise do parasitismo foram: (1) ocorrência de parasitos e sítios de infecção, (2) classificação dos parasitos, (3) doenças nos peixes e zoonoses, (4) dinâmica do parasitismo (sazonalidade e ciclo de vida de parasitos). Trechos das respostas mais representativas, obtidos a partir da transcrição das gravações, foram apresentados ao longo do texto visando elucidação das perspectivas, analisadas por interpretação do contexto.

Para a análise quantitativa foram contabilizadas as respostas referentes ao conhecimento dos entrevistados sobre a ocorrência do parasitismo nos animais, sendo apresentadas as frequências, como sugerido por Rosa e Orey (2014). Quando necessário, para algumas das categorias de análise do parasitismo, são apresentadas as frequências das respostas.

\section{RESULTADOS E DISCUSSÃO}

\subsection{Saberes tradicionais sobre ocorrência de ictioparasitos e sítios de infecção}

Todas as espécies de peixes apresentadas nas imagens foram reconhecidas pelos participantes das duas comunidades, exceto a espécie controle (A. jurubatibensis) que, 
consequentemente, também não foi indicada como parasitada. Isto pode garantir a confiabilidade das respostas dos participantes, indicando haver domínio dos componentes ambientais da região (CLAUZET et al., 2007).

Todos os participantes de Jaguaripe e 88\% dos entrevistados em Nazaré demonstraram ter conhecimento sobre a ocorrência de ictioparasitos em alguma espécie de peixe. Para Herbst e Hanazaki (2014), é comum pescadores relatarem infecções parasitárias em peixes, tendo os autores obtido o relato de $58 \%$ dos entrevistados na região costeira de Santa Catarina. Os resultados obtidos para o Rio Jaguaripe demonstraram que, apesar dos parasitos de peixes serem considerados“ componentes ocultos da biodiversidade” (LUQUE, 2008) e subestimados nas pesquisas acadêmicas (ROCHA et al., 2016), fazem parte da rotina dos pescadores, sendo por eles reconhecidos e interpretados, representando parte do conhecimento ecológico local.

Espécies de peixes indicadas como não parasitadas foram consideradas por $27,7 \%$ dos entrevistados da comunidade de Jaguaripe e 11,1\% dos participantes de Nazaré como "peixes limpos" ou de "carne limpa", revelando a possível existência de um sentimento de nojo ou comportamento de repulsa aos parasitos. Um participante de Jaguaripe afirmou ser a “carne boa" por não ter vermes. No Brasil, é comum os invertebrados provocarem repulsa (LEWINSOHN et al., 2005) e este comportamento, juntamente ao nojo, são considerados comportamentos selecionados naturalmente, que levam à evitação de ecto e endoparasitos e, consequentemente, redução da chance de transmissão de doenças (PROKOP E FANČOVIČOVÁ, 2010). Adicionalmente, um ser vivo habitando os corpos dos peixes, pode ser visto como um invasor indesejado, como ocorre com o parasitismo em humanos.

Dentre os espécimes de peixes fornecidos pelos participantes de Nazaré e as imagens de peixes apresentadas, quatro foram apontadas como parasitadas (Tabela 1), sendo elas, espécie de valor comercial. Um dos entrevistados citou uma espécie (etnonome "olho-deboi”) que não foi apresentada, como tendo parasitos.

Hoplias malabaricus, a traíra, uma das espécies mencionadas pelos participantes de Nazaré, é um peixe carnívoro, conhecido por abrigar grande riqueza de parasitos, tendo sido listadas 50 espécies de diferentes grupos taxonômicos (GIÃO et al., 2020). Este peixe tem importância na pesca brasileira (FROESE e PAULY, 2019).

Para Gymnotus spp., gênero a que pertence outra espécie citada, foram relatadas 16 espécies de parasitos no Brasil (ISAAC et al., 2004). Espécies de Gymnotus são usadas como 
Dantas et al. Conhecimento tradicional dos pescadores artesanais sobre os parasitos de peixes do rio Jaguaripe, Bahia, nordeste do Brasil. Ethnoscientia V.6, n.1, 2021. DOI: 10.22276/ethnoscientia.v6i1.339

isca viva para a pesca esportiva (RESENDE et al., 2006), assim como para pesca tradicional na região:

"Enfia amoreia nas iscas." (Pescador de Jaguaripe).

Para o gênero Sphoeroides, há registros de diferentes táxons em várias partes do mundo, incluindo o Brasil (MARTÍNEZ-AQUINO et al., 2020; FAJER-ÁVILA et al., 2011; ÁLVAREZ-BORREGO e FÁJER-ÁVILA, 2006; DYKOVÁ et al., 2002; THATCHER, 2001; VIDAL-MARTÍNEZ e MENDOZA-FRANCO, 2008). Sphoeroides spengleri tem importância ornamental (FROESE e PAULY, 2019), mas 51,8\% dos participantes em ambas as comunidades disseram que o peixe é consumido. Os registros científicos de parasitos nestes três táxons de peixes endossam o conhecimento tradicional local.

$\mathrm{Na}$ comunidade de Jaguaripe foi relatado o parasitismo para $60 \%$ das espécies de peixes apresentadas. As demais representam peixes sem valor comercial ou que não fazem parte da rotina de pesca. As maiores frequências de relato de parasitismo $(>10 \%)$, concentraram-se nas espécies de elevado valor comercial e abundantes, tais como Centropomus parallelus Poey, 1860 (Tabela 1). O peixe é reconhecidamente valorizado na região do Recôncavo Sul da Bahia, devido à grande apreciação gastronômica (PUGAS e MATEUS, 2016) e representa importante recurso pesqueiro brasileiro (IBAMA, 2011). Três relatos de pescadores de Jaguaripe corroboram o valor econômico do robalo na localidade:

\footnotetext{
"É o peixe mais caro aqui na região."

"O peixe mais caro que temos aqui, ele é muito valorizado e entra muita lancha de fora pra pegar ele aqui."

"O mais caro de todos."
}

Metade dos participantes da comunidade de Jaguaripe e 11,1\% de Nazaré afirmaram que a espécie $S$. spengleri é bastante parasitada:

"Onde acha mais aquelas lombrigas [...] é no baiacu." (Pescador de Jaguaripe)

"Todos que têm verme, o baiacu nasce uma mancha preta." (Pescador de Nazaré)

Uma possível explicação para a abundância dessas narrações em comparação aos demais peixes subutilizados se deve ao fato dessa espécie, quando tratada para consumo, exigir o máximo de atenção, como observado por pescadores participantes de Jaguaripe:

"Ele é venenoso e tem um modo de tratar ele [...] só algumas pessoas que sabem tratar, porque se não tirar o fér e o umbigo direito..."

"Ele é venenoso, tem que saber tirar ou mata, chama fel, fica na barriga." 
As falas dos participantes são corroboradas por dados publicados. O peixe é considerado sarcotóxico e, se ingerido sem o preparo por pessoa habilitada, causa acidentes tetrodontóxicos por conter bloqueadores neuromusculares que podem levar à paralisia e óbito por falência respiratória (BRASIL, 2001). A tetrodotoxina concentra-se em diferentes regiões como pele, gônadas e fígado (ROCHA et al., 2002).

Tabela 1: Saberes etnoictioparasitológicos de pescadores dos municípios de Nazaré (N) e Jaguaripe (J) acerca das espécies de peixes do Rio Jaguaripe, Bahia, Brasil. * Espécies mais frequentemente citadas como parasitadas ( $>10 \%$ dos relatos).

\begin{tabular}{|c|c|c|}
\hline $\begin{array}{c}\text { Etnonomes das espécies de peixes } \\
\text { parasitadas }\end{array}$ & $\begin{array}{l}\text { Nome científico dos peixes } \\
\text { parasitados* }\end{array}$ & $\begin{array}{l}\text { Frequência de } \\
\text { citações }(\%)\end{array}$ \\
\hline Cabeçudo, Xaréu & Caranx sp. & $87,5(\mathrm{~J})$ \\
\hline Robalo & Centropomus parallelus Poey, 1860 & $87,5(\mathrm{~J}) ; 11,1(\mathrm{~N})$ \\
\hline Vermelho, Carapitanga, Cioba & Lutjanus sp. & $62,5(\mathrm{~J})$ \\
\hline Traíra & Hoplias malabaricus (Bloch, 1794) & $66,6(\mathrm{~N})$ \\
\hline Amoreia-preta, lampreia & Gymnotus carapo Linnaeus, 1758 & $11(\mathrm{~J}) ; 55,5(\mathrm{~N})$ \\
\hline Pescada-branca, Pescada- amarela & Cynoscion sp. & $50(\mathrm{~J})$ \\
\hline Baiacu, Baiacu-mirim & Sphoeroides spengleri (Bloch, 1785) & $50(\mathrm{~J}) ; 11,1(\mathrm{~N})$ \\
\hline Paru & Chaetodipterus faber (Broussonet, 1782) & $25(\mathrm{~J})$ \\
\hline Carapeba & Diapterus sp. & $25(\mathrm{~J})$ \\
\hline Arraia & $\begin{array}{l}\text { Hypanus guttatus (Bloch \& Schneider, } \\
\text { 1801) }\end{array}$ & $12,5(\mathrm{~J})$ \\
\hline
\end{tabular}

O saber tradicional etnoictioparasitológico envolveu tanto ectoparasitos (que habitam partes superficiais do corpo ou que sejam diretamente banhadas por água do meio) quanto endoparasitos (que habitam os órgãos internos), em Nazaré e em Jaguaripe.

Alguns exemplos de falas sobre endoparasitos são:

"[...] gente também é assim, tem no intestino e tudo que é lugar." (Pescador de Nazaré)

"Tem vez que fica aquelas vermes compridinhas [...] só na parte das tripas." (Pescador de Jaguaripe)

Conhecimentos sobre ectoparasitos incluem:

"Ele tem aquelas lombriguinhas pretas na boca." (Pescador de Jaguaripe)

"Aqueles bichinhos pretos na parte da carne." (Pescador de Jaguaripe)

"Dentro da boca e na guelra." (Pescador de Jaguaripe) 
"[...] o baiacu nasce uma mancha preta, nasce na carne [...]" (Pescador de Nazaré)

"[...] tem o verme na carne [...] você pega a carne e quando puxa ele sai assim." (Pescador de Nazaré)

Os participantes de Nazaré especificaram apenas dois sítios de infecção, sendo eles a "carne" (musculatura somática) e o intestino citados por dois entrevistados. Entre os entrevistados de Jaguaripe, foram lembradas a carne $(83,3 \%)$, a boca $(88,8 \%)$, a pele/escama (44,4\%), a cabeça (27,7\%), a guelra (brânquia) (22,2\%) e as tripas (vísceras 16,6\%).

O reconhecimento de sítios internos e externos demonstra observação minuciosa durante o trato dos animais para comercialização ou consumo. Revela ainda a possível curiosidade que animais associados aos peixes despertam nos pescadores.

\subsection{Etnonomes dos ictioparasitos}

Quanto aos grupos taxonômicos de parasitos, os entrevistados das duas comunidades utilizaram caracteres morfológicos na descrição, indicando morfologia compatível com os grupos Trematoda, Nematoda e Crustacea, que têm inúmeros representantes parasitos de peixes (RUPPERT et al., 2005). Este conhecimento etnoictioparasitológico local vai de encontro ao que existe registrado na literatura para as espécies de peixes citadas (Tabela 2).

Tabela 2: Comparação do conhecimento tradicional de pescadores artesanais do Rio Jaguaripe, Bahia, colônia de Pescadores do município de Nazaré $(\bullet)$ e do município de Jaguaripe ( ) com informações da literatura científica para algumas espécies de peixes citadas como parasitadas. ${ }^{1}=$ Luque et al. (2011); ${ }^{2}=$ Moravec et al. $(2008) ;{ }^{3}=$ Luque et al. $(2013) ;{ }^{4}=$ Luque e Tavares (2007); ${ }^{5}=$ Ventura et al. (2018); ${ }^{6}=$ Scholz et al. (2001); ${ }^{7}=$ Mejía-Madrid e Aguirre-Macedo (2011).

\footnotetext{
Grupo de Parasito/ Falas usando etnonomes para Algumas espécies de parasitos em publicações Espécie de peixe as espécies de ictioparasitos científicas
} 
Caranx sp.

Centropomus parallelus Poey, 1860

Cynscion sp.

Chaetodipterus faber (Broussonet, 1782) "Na guelra tem uma barata
que gruda, ela geralmente dá
em outros peixes também."

"Tem tempo que ele tá cheio de vermezinho, quando a gente tem umas lombrigazinhas que dizem que é da carne dele mesmo $[\ldots]$ ",

"Dentro da boca e barata acha também."

"Na boca do peixe a gente chama de baratinha."

"Barata acha, gosta mesmo da guelra." retalha ele ou na cabeça ele

Isópodes Cymothoa oestrum (Linnaeus, 1758) e Cymothoa brasiliensis Schiödte and Meinert, $1884^{1}$ na boca e brânquias ${ }^{1}$

Nematoides Contracaecum sp. no mesentério; Cucullanus pulcherrimus Barreto, 1918 e Philometra sp. no intestino; Raphidascaris sp., Terranova sp., Anisakis sp., Contracaecum sp., Hysterothylacium sp. e Terranova sp. no mesentério de Caranx spp.

Nematoide Philometra sp. no tecido subcutâneo de Caranx hippos (Linnaeus, 1766) ${ }^{2}$

Isópodes Cymothoa oestrum (Linnaeus, 1758) na boca e brânquias e Cymothoa recifea Thatcher \& Fonseca, 2005 na boca $^{3}$

Isópode Lironeca redmanni Leach, 1818 , na câmara branquial e na boca ${ }^{3}$

Copépodes Anuretes anurus (Bere, 1936) na superfície do corpo e brânquias e Anuretes heckelli (Krøyer, 1863) na cavidade branquial, Caligus flexispina Lewis, 1964 nas brânquias, Caligus haemulonis Krøyer, 1863 na superfície do corpo e brânquias, Caligus mutabilis Wilson, 1905 na cavidade branquial e brânquias e Caligus praetextus Bere, 1936 na superfície corporal e brânquias, Lernanthropus pupa Burmeister, 1833 nas brânquias ${ }^{4}$

Gymnotus carapo "[...] tem épocas que tem Larvas de nematoides Eustrongylides sp. na (Linnaeus, 1758) lombriga e outras não. Igual a musculatura, mesentério e parede do estômago; gente, às vezes tem e outras Capillariinae, Contracaeum sp., Hysterothylacium não. A gente também é assim, sp., Brevimulticaecum sp. e Spiroxys sp. no tem no intestino e tudo que é mesentério; nematoides adultos Rondonia rondoni lugar."
Travassos, 1920 e Procamallanus (Procamallanus) peraccuratus Pinto, Fábio, Noronha \& Rolas no intestino1,5

\section{Continuação}

Tabela 2: Comparação do conhecimento tradicional de pescadores artesanais do Rio Jaguaripe, Bahia, Colônia de Pescadores do município de Nazaré ( ) e do município de Jaguaripe ( ) com informações da literatura científica para espécies de peixes citadas como parasitadas. ${ }^{1}=$ Luque et al. $(2011) ;{ }^{2}=$ Moravec et al. (2008); ${ }^{3}=$ Luque et al. (2013); ${ }^{4}=$ Luque e Tavares (2007); ${ }^{5}=$ Ventura et al. $(2018) ;{ }^{6}$ $=$ Gueretz et al. $(2020) ;{ }^{7}=$ Barros et al. $(2007) ;{ }^{8}=$ Scholz et al. $(2001) ;{ }^{9}=$ Mejía-Madrid e AguirreMacedo (2011). 
Grupo de Parasito/ Espécie de peixe
Falas usando etnonomes para as espécies de ictioparasitos

\section{Algumas espécies de parasitos em publicações científicas}

Hoplias malabaricus (Bloch, 1794)

\author{
"Tem época que nós abrimos a \\ barriga dela, tem vários tipos \\ de vermes $[\ldots]$ que não \\ sabemos identificar."
}

Trematódeo Ithyoclinostomum sp. na boca, brânquia,cavidade, esôfago, fígado, musculatura, opérculo e nematoide Eustrongylides sp. no fígado ${ }^{6}$

Nematoide Contracaecum sp. na musculatura esquelética e vísceras ${ }^{7}$

Sphoeroides spengleri (Bloch, 1785)
"O baiacu nasce uma mancha
preta [...] nasce na carne." No baiacu fica aquelas pintas pretas e dentro as lombrigas branca."
Metacercárias de Heterophyidae (Trematoda) nas brânquias, nadadeiras e músculos de Sphoeroides testudineus (Linnaeus, 1758) ${ }^{8}$

Cucullanus dodsworthi (Nematoda) no intestino de $S$. testudineus 9

Dois participantes da região de Nazaré, mencionaram os etnonomes "lombriga" e "mancha preta" ou "pinta preta" para os ictioparasitos observados. Oitenta e oito porcento dos participantes de Jaguaripe fizeram comentários semelhantes. O etnonome "lombriga" quando associado ao sítio de infecção "carne", possivelmente, se refere a nematoides encistados na musculatura, como ilustrado na Figura 2a. A ocorrência de nematoides anisaquídeos, por exemplo Anisakis simplex e Pseudoterranova decipiens, na musculatura somática de diferentes espécies de peixes é comum (LYMBERY e CHEAH, 2007), corroborando o saber etnoictioparasitológico local. Quando associados ao sítio "intestino" ou "tripas", parecem se referir a nematoides adultos. A maior parte dos Nematoda infectam o trato intestinal de seus hospedeiros (MOLNÁR et al., 2006).

Os etnonomes "pinta preta" ou "mancha preta", provavelmente, se referem a larvas metacercárias de Trematoda (Figura 2b). Alguns tipos são conhecidos por causarem a chamada "doença dos pontos pretos" ou black spot disease (PAPERNA e DZIKOWSKI, 2006), devido a este aspecto notado pelos participantes. Um participante de Jaguaripe relacionou o parasito a "qualquer baiacu", já que outras quatro espécies ocorrem na região (LOPES et al., 1998). Apesar de larvas de Nematoda e Trematoda serem comuns em diversas espécies de peixes de água doce (PAVANELLI et al., 2013) e marinhos (LUQUE et al., 2011; GIBSON et al., 2002), não há registros destes parasitos em S. spengleri. Para espécie congenérica - Sphoeroides testudineus (Linnaeus, 1758) - se conhece diferentes espécies de metazoários parasitos externos e internos (MEJÍA-MADRID e AGUIRRE-MACEDO, 2011; 
MARTÍNEZ-AQUINO et al., 2020; SCHOLZ et al., 2001). Este resultado indica que o conhecimento tradicional sobre os ictioparasitos pode levantar hipóteses acerca da diversidade parasitária a ser explorada cientificamente na região.

Apesar de três grupos taxonômicos de parasitos terem sido reconhecidos através das entrevistas, não foi possível identificar espécies de parasitos, da mesma forma que Herbst e Hanazaki (2014) em estudo com tainhas do Sudeste do Brasil.

Em Jaguaripe, 50\% dos participantes afirmaram ser comum em Caranx sp., $C$. parallelus, Cynoscion sp., S. spengleri e C. faber, um parasito com o etnonome "barata", "baratinha" e "baratazinha" na boca e na guelra. O mesmo termo (barata) foi utilizado por pescadores do Sudeste do Brasil, para parasitos presos ao corpo de tainhas (HERBST e HANAZAKI, 2014). Com base nas descrições e sítios de infecção apontados pelos pescadores entrevistados, pressupõe-se que esses parasitos pertençam ao grupo Isopoda. A maioria das observações concorda com informações obtidas na literatura científica parasitológica apresentadas na Tabela 2. A figura 3 ilustra a morfologia desses parasitos observados em peixes do Rio Jaguaripe.

Para C. faber, no entanto, há apenas registros publicados de Copepoda parasitando os sítios de infecção citados (Tabela 2). Uma possível explicação é a de que Lernanthropus pupa Burmeister, 1833, uma das espécies de Copepoda registrada no peixe tem grande tamanho como outras espécies congenéricas (TOKȘEN et al., 2008) tendo recebido por isso, o entonome de "barata". É possível ainda que o saber ictioparasitológico tradicional no Rio Jaguaripe esteja indicando uma espécie ainda não registrada em C. faber.

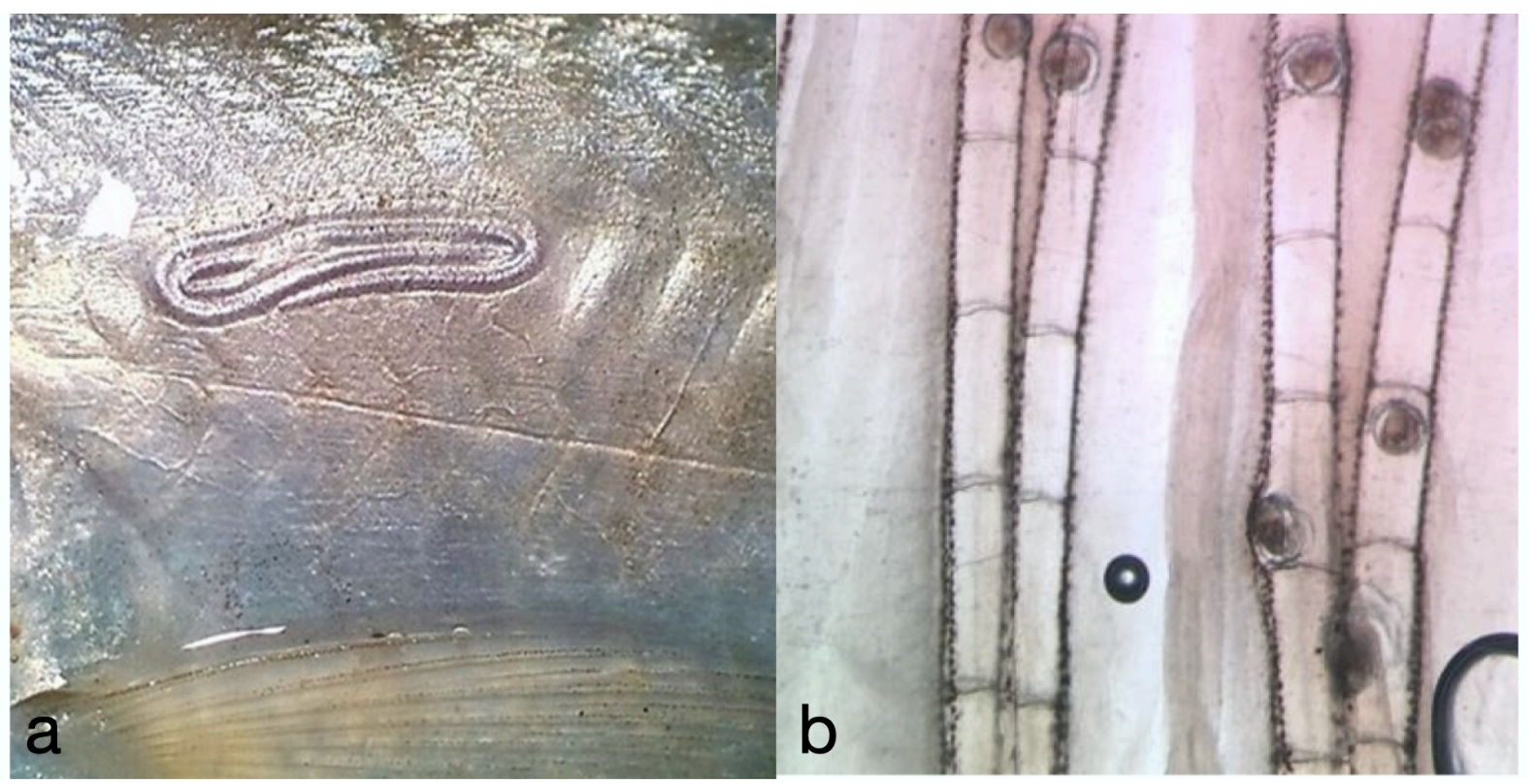


Figura 2: Parasitos com morfologia coincidente às citadas por pescadores do rio Jaguaripe. a) Larva de Nematoda parasitando a parede corporal de Caranx latus Agassiz, 1831 do rio Jaguaripe, Bahia. b) Metacercárias de Trematoda encistadas nos raios das nadadeiras de Sphoeroides sp. (Banco de imagens dos autores).

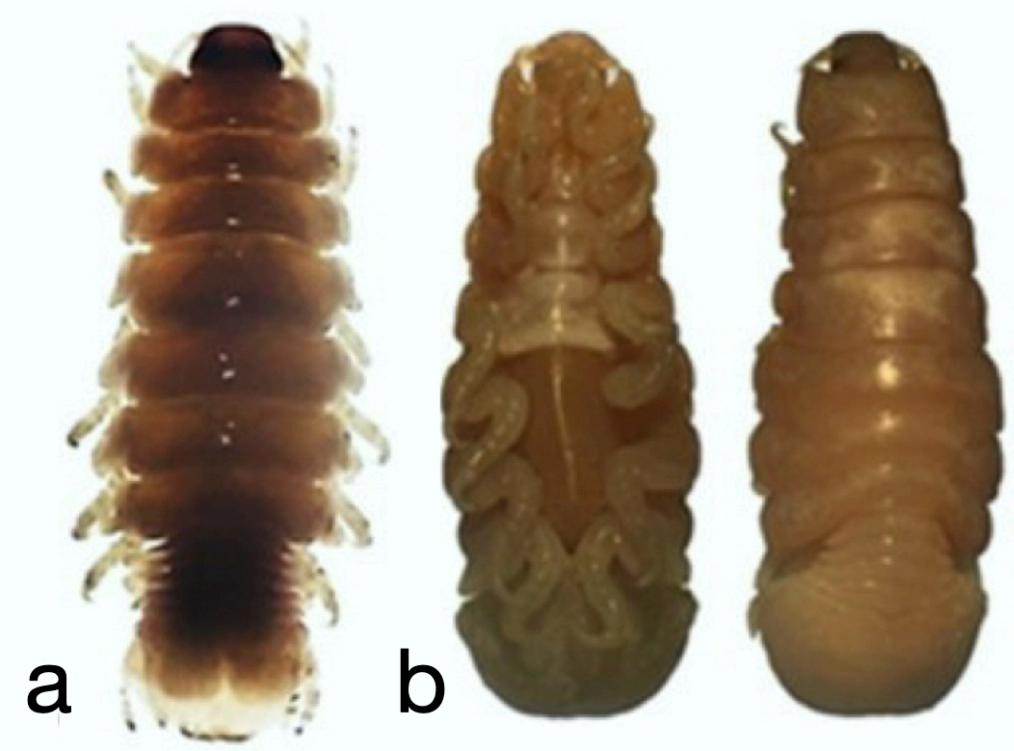

Figura 3: Isópodes parasitos de Caranx spp. a) Telotha sp.; b) Cymothoa ianuarii Schioedte \& Meinert, 1884. (Banco de imagens dos autores).

Houve ainda a denominação "pulga" para ictioparasitos por 22,2\% dos participantes da colônia de Jaguaripe, provavelmente se referindo a Copepoda ou Branchiura, comuns em peixes marinhos (LUQUE et al., 2013) e de água doce (LIMA et al., 2013). Estes parasitos são conhecidos na literatura científica pelo nome popular de piolho-de-peixe (DUARTE et al., 2020) ou piolho-do-mar (MORALES-SERNA et al., 2016). O termo "piolho" tem registro na literatura etnoictiológica, possivelmente, referindo-se também a crustáceos isopódes em Sciaenidae no Pará (BARBOZA e PEZZUTI, 2011).

Os resultados referentes à classificação mostraram, portanto, que os pescadores da região de estudo utilizam as características morfológicas dos parasitos e as comparam com aquelas de animais de grupos taxonômicos próximos e muito conhecidos, no caso outros artrópodes. Nenhum participante relacionou a forma desses animais com algum outro tipo de crustáceo, como camarões, por exemplo. A relação foi feita apenas com outros parasitos (pulga) ou com praga urbana (barata).

\subsection{Doenças ícticas e zoonoses associadas a ictioparasitos}

Quanto às doenças causadas pelos parasitos nos peixes, 22,2\% dos participantes de 
Nazaré e $38,8 \%$ de Jaguaripe relataram efeitos negativos para o peixe hospedeiro apenas na presença de Crustacea Isopoda, indicando prejuízos causados pelos parasitos, por exemplo hematofagia, inanição e perda de peso:

"A amoreia tem uns [...] que suga o sangue do bicho." (Pescador de Nazaré)

"Na boca do peixe a gente chama de baratinha [...] muitos peixes morrem, porque ele empata o peixe de comer [...] no céu da boca." (Pescador de Jaguaripe)

"[...] quando ele tá magro é que tá com o verme." (Pescador de Jaguaripe)

O hábito hematófago dos Isopoda destacado por voluntários encontra amparo científico (RAMESHKUMAR e RAVICHANDRAN, 2010), assim como os seus efeitos na saúde do peixe, tanto de cativeiro quanto silvestres, entre eles perda de peso, alterações hematológicas e no crescimento, redução na fertilidade e mortalidade (LESTER e HAYWARD, 2006).

Houve um reconhecimento da capacidade de Isopoda se prender ao peixe, devido à existência de especializações dos pereopódes, funcionando como pernas preênseis:

"O cabeçudo gosta de ter tipo uma barata [...] o cabeçudo é veseiro em achar isso [...] ela enterra aquelas unhas assim onde ela tá e não larga assim, só se você garrar assim com a mão e puxar."

De acordo com SMIT et al. (2014) inúmeras adaptações são requeridas para uma vida parasitária, tais como os ganchos nas extremidades dos pereópodes que permitem a fixação.

Em relação às zoonoses, 100\% dos participantes de Nazaré e de Jaguaripe, demonstraram desconhecimento ou despreocupação sobre a possibilidade de os peixes transmitirem doenças para o homem:

“O verme não incomoda nada, é injetada dentro da carne do peixe e não
empata nada, tirou e acabou, pode cozinhar e comer." (Pescador de Nazaré)
" [...] o xaréu [...] uns vermezinhos compridinho, uma linha escura [...] faz
mal pra gente náo que já comi tanto que se tiver de ter algum probrema já
tinha acontecido." (Pescador de Jaguaripe)
"Não sei se faz mal pro peixe e pra gente não, porque a gente come e não sente
nada." (Pescador de Jaguaripe)

Este conjunto de conhecimentos diverge do que se conhece cientificamente. Diversas espécies de parasitos de peixes têm potencial zoonótico. Sabe-se que larvas de Trematoda, por exemplo Ascocotyle (Phagicola) longa Ransom, 1920, que infecta as vísceras de tainhas, é o agente etiológico da fagicolose humana (GUERETZ et al., 2019). Metacestoides de 
Diphyllobothrium latum foram registrados como causadores de um surto de difilobotríase humana em São Paulo (EDUARDO et al., 2005). Larvas de Nematoda podem alcançar os músculos somáticos através de migração após a morte do hospedeiro, o que é comum para nematoides anisaquídeos (LYMBERY e CHEAH, 2007). Existem registros de larvas da família em diferentes espécies de peixes marinhos e de água doce no Brasil (LUQUE et al., 2011), com apenas um relato confirmado em humanos (CRUZ et al., 2010) e alguns sem confirmação (AMATO NETO et al., 2007).

Para Chai et al. (2005), zoonoses transmitidas pela carne, como triquinelose e cisticercose, são mais familiares, ao contrário daquelas transmitidas por peixes, apesar destas serem responsáveis por muitas infecções humanas ao redor do mundo. Doenças zoonóticas transmitidas por artrópodes e animais domésticos, por exemplo, foram mais reconhecidas em comunidades no Nordeste (NUNES et al., 2011b; SOUZA et al, 2011). O desconhecimento das zoonoses transmitidas pelos peixes por parte de uma comunidade pode representar risco potencial à saúde pública local.

\subsection{Dinâmica do parasitismo}

A sazonalidade foi o aspecto mais relevante da dinâmica do parasitismo percebido pelos participantes. Este esteve presente nas respostas de 77,7\% dos voluntários de Jaguaripe e 55,5\% de Nazaré, algumas vezes com precisão temporal. Como exemplo:

"Só a amorea que dá nesse São João e a traíra também em mês de São João não pode usar ela, porque elas têm um verminho, sabe?" (Pescador de Nazaré)

"Em épocas que têm lombriga e outras não." (Pescador de Nazaré)

"Acha mais no inverno, no verão não acha muito assim não, é só dele mesmo." (Pescador de Jaguaripe)

"O tempo é outubro e novembro, nos outros meses não tem." (Pescador de Jaguaripe)

Devido a variações nas condições do ambiente, das populações de invertebrados hospedeiros intermediários e flutuações temporais de variáveis físicas e químicas da água, os diferentes grupos de parasitos apresentam variação temporal, tanto na ocorrência quanto no tamanho das populações (WOO, 2006). Eventos como a variação temporal na dieta do hospedeiro e a disponibilidade de estágios infectantes também influenciam na variação sazonal dos parasitos de peixes (NEGREIROS et al., 2019).

A maioria dos participantes das duas colônias demonstraram desconhecimento sobre a transmissão dos parasitos aos peixes. Todos os voluntários de Nazaré não relacionaram 
parasitos com outros animais atuantes nos seus ciclos de vida, ou com as cadeias alimentares. Quando indagados sobre como o parasito chega no peixe, disseram não saber. Em Jaguaripe, ocorreu o mesmo. Na opinião de $94,4 \%$ dos participantes desta colônia, os parasitos aparecem ali e são exclusivos de peixes:

\section{"[...] ele fica só no peixe [...]" \\ "[...] acho que é cria dela mesmo [...]"}

Apenas um voluntário de Jaguaripe relacionou um tipo de parasito a outro animal:

"Dificil achar, mas tem [...] e dá no siri também quando tá na maré, mas esse é mais dificil achar."

Portanto, os dados etnoecológicos para esse aspecto do parasitismo difere do que é reconhecido cientificamente, com vários parasitos participando e necessitando da teia trófica para completar seus ciclos de vida complexos. Isto explica, em parte, o desconhecimento das zoonoses, pois a circulação dos parasitos na teia trófica não é reconhecida.

Possivelmente, a percepção de que os componentes do ecossistema estão interligados, ocorre mais facilmente para "processos ecológicos" observáveis e do cotidiano dos pescadores (por exemplo, a relação entre disponibilidade de alimento para uma espécie de peixe e maior abundância desta espécie). Ao contrário, processos que não são passíveis de observação direta (como as transmissões parasitárias) podem ser menos percebidos.

Apesar do conjunto de saberes tradicionais da comunidade estudada ser rico, a compreensão de processos ambientais na sua totalidade é sempre relevante. A partir dela, se reconhece a importância de proteger o meio ambiente como um todo (BARBOSA et al., 2017). Esta compreensão pode ser alcançada inserindo-se aspectos, tais como o parasitismo e sua dinâmica natural, como parte do processo de educação ambiental. Parasitos são componentes importantes que podem interferir no funcionamento de um ecossistema, a exemplo da "manipulação" que exercem nas relações alimentares (FREDENSBORG e LONGORIA, 2012) e devem ser sempre considerados.

\section{CONCLUSÕES}

O conjunto de conhecimentos expresso pelos pescadores artesanais do Rio Jaguaripe mostrou que o ictioparasitismo e partes da sua dinâmica são temas notados, interpretados e, portanto, podem ser difundidos na comunidade. Por outro lado, as transmissões parasitárias e a possibilidade dos ictioparasitos causarem doenças no homem são aspectos desconsiderados 
pelo saber local, podendo representar risco para a saúde. Inserir o ictioparasitismo e sua dinâmica natural como parte do processo de educação ambiental é uma estratégia para ampliar este conhecimento.

\section{AGRADECIMENTOS}

À FINEP (Financiadora de Estudos e Projetos) pelo apoio financeiro para a implantação do Núcleo de Sanidade Aquícola na UFRB.

\section{REFERENCIAS BIBLIOGRÁFICAS}

ABO-EL-SOOUD, K. Ethnoveterinary perspectives and promising future. International Journal of Veterinary Science and Medicine, v. 6, n. 1, p. 1-7, 2018.

ALBUQUERQUE, U. P.; RAMOS, M. A.; LUCENA, R. F. P.; ALENCAR, N. L. Methods and Techniques Used to Collect Ethnobiological Data. In: ALBUQUERQUE, U. P.; CUNHA,

L. V. F. C.; LUCENA, R. F. P.; ALVES, R. R. N. (Eds.). Methods and Techniques in Ethnobiology and Ethnoecology. Nova Iorque: Springer. 2014. p. 15-37.

ÁLVAREZ-BORREGO, J.; FÁJER-ÁVILA, E. J. Identification of platyhelminth parasites of the wild bullseye pufferfish (Sphoeroides annulatus Jenyns, 1853) using invariant digital color correlation. Revista de Biología Marina y Oceanografía, v. 41, n.1, p. 129 - 139, 2006.

AMATO NETO, V.; AMATO, J. G. P.; AMATO, V. S. Letter to the editor: Probable recognition of human anisakiasis in Brazil. Revista do Instituto de Medicina Tropical de São Paulo, v. 49, n. 4, p. 261-262, 2007.

ARAÚJO, L. S.; MAFALDA JR., P. O; MOREIRA. Í. T. A. Avaliação de HPAs nos manguezais dos Estuários dos Rios São Paulo e Jaguaripe, Bahia de Todos os Santos, Bahia. Revista Brasileira de Gestão Ambiental e Sustentabilidade, v. 5, n. 10, 2018.

ARRUDA, J. C.; SILVA, C. J.; SANDER, N. L.; PULIDO, M. T. Conhecimento ecológico tradicional da ictiofauna pelos quilombolas no Alto Guaporé, Mato Grosso, Amazônia meridional, Brasil. Boletim do Museu Paraense Emílio Goeldi. Ciências Humanas, v. 13, n. 2, p. 315-329, 2018.

AUGUSTO, L. Porta do Sertão. $3^{\text {a }}$ Edição. Nazaré: Kouraça, 1995. 239 p.

BAILEY K. Methods of social research. $2^{\text {a }}$ Edição. Nova Iorque: The Free Press, Macmillan Publishers, 1982. $553 \mathrm{p}$.

BARBOZA, R. S. L.; PEZZUTI, J. C. B. Etnoictiologia dos pescadores artesanais da Resex Marinha Caeté-Taperaçu, Pará: aspectos relacionados com etologia, usos de hábitat e migração de peixes da família Sciaenidae. Sitientibus série Ciências Biológicas, v. 11, n. 2, p. 133-141, 2011. 
BARBOSA, H. O.; SOUZA, M. F.; ONDEI, L. S.; TERESA, F. B. Conhecimento ecológico local e percepção dos impactos ambientais por moradores da zona rural sobre riachos e peixes da bacia do alto Rio Tocantins, Goiás, Brasil. Ethnoscientia, v. 2, 2017.

BARROS, F. B. Etnoecologia da pesca na reserva extrativista Riozinho do Anfrísio - Terra do Meio, Amazônia, Brasil. Amazônica, v. 4, n. 2, p. 286-312, 2012.

BARROS, L. A.; MORAES FILHO, J.; Oliveira, R. L. Larvas de nematóides de importância zoonótica encontradas em traíras (Hoplias malabaricus Bloch, 1794) no município de Santo Antonio do Leverger, MT. Arquivo Brasileiro de Medicina Veterinária e Zootecnia, v. 59, n. 2, p. 533-535, 2007.

BEGOSSI, A.; SALIVONCHYK, S. V.; ARAUJO, L. G.; ANDREOLI, T. B.; CLAUZET, M.; MARTINELLI, C. M.; FERREIRA, A. G. L.; OLIVEIRA, L. E. C.; SILVANO, R. A. M. Ethnobiology of snappers (Lutjanidae): target species and suggestions for management. Journal of Ethnobiology and Ethnomedicine, v. 7, n. 11, p. 1-22, 2011.

BEGOSSI, A.; SALYVONCHYK, S.; NORA, V.; LOPES, P. F.; SILVANO, R. A. M. The paraty artisanal fishery (Southeastern Brazilian coast): ethnoecology and management of a social-ecological system (SES). Journal of Ethnobiology and Ethnomedicine, v. 8, n. 2, p. $1-18,2012$.

BERKES, F. Toward a unity of mind and nature. In: VIEIRA, P. F. (Org.) Conservação da diversidade biológica e cultura em zonas costeiras. Florianópolis: APED, 2003. p. 115143.

BEZERRA, M. Cuidado com o sushi: população de vermes do prato cresceu 283x em 40 anos. 2020. Disponível em: <https://www.uol.com.br/tilt/noticias/redacao/2020/03/25/risco-asaude-populacao-de-vermes-do-sushi-cresce-283-vezes-em-40-anos.htm?> Acesso em: 10 de out. 2020.

BRASIL - Ministério da Saúde, Conselho Nacional de Saúde. Resolução 466/2012, Brasília, DF, 2013, 12 p. Disponível em:< http://www.conselho.saude.gov.br/resolucoes/2012/ Reso466.pdf $>$. Acesso em: 20 de janeiro de 2016.

BUCHMANN, K.; MEHRDANA, F. Effects of anisakid nematodes Anisakis simplex (s.1.), Pseudoterranova decipiens (s.1.) and Contracaecum osculatum (s.1.) on fish and consumer health. Food and Waterborne Parasitology, v. 4, p. 13-22, 2016.

CARVALHO, A. Conhecimento ecológico tradicional no fragmento da planície de inundação do alto rio Paraná: percepção ecológica dos pescadores. Acta Scientiarum, v. 24, n. 2, p. 573-580, 2002.

CHAI, J.; MURRELL, K. D.; LYMBERY, A. J. Fish-borne parasitic zoonoses: status and issues. International Journal for Parasitology, v. 35, p. 1233-1254, 2005.

CLAUZET, M.; RAMIRES, M.; BEGOSSI, A. Etnoictiologia dos pescadores artesanais da praia de Guaibim, Valença (BA), Brasil. Neotropical Biology and Conservation, v. 2, n. 3, 
Dantas et al. Conhecimento tradicional dos pescadores artesanais sobre os parasitos de peixes do rio Jaguaripe, Bahia,

p. 136-154, 2007.

COSTA-NETO, E. M.; ANDRADE, C. T. S.; COUTO, D. F.; MAGAlHÃES, H. F. Diagnóstico etnoecológico em comunidades pesqueiras do município de Conde, região litoral norte do Estado da Bahia. Ethnoscientia, v. 4, p. 2-21, 2019.

CRUZ, A. R.; SOUTO, P. C. S.; FERRARI, C. K. B.; ALlEGRETTI, S. M.; ARRAISSILVA, W. W. Endoscopic imaging of the first clinical case of anisakidosis in Brazil. Scientia Parasitologica, v. 11, n. 2, p. 97-100, 2010.

DEMARTINI, M. Popularização do sushi aumenta casos de infecção por parasitas. Exame, 2017. Disponível em: <https://exame.com/ciencia/numero-de-casos-de-infeccao-por-parasitaaumenta-devido-ao-sushi/>. Acesso em: 25 de ago. 2020.

DIEGUES, A. C.; ARRUDA, R.; SILVA, V.; FIGOLS, F.; ANDRADE, D. (Org.). Os Saberes Tradicionais e a Biodiversidade no Brasil. São Paulo: NUPAUB-USP/MMA Press., 2000.

DUARTE, R.; ALMEIDA-BERTO, M. F. C.; CALVARIO, C. F.; SANTOS-CLAPP, M. D.; BRASIL-SATO, M. C. Argulus elongatus (Branchiura, Argulidae) in fish in the upper São Francisco river, Brazil. Brazilian Journal of Veterinary Parasitology, v. 29, n. 2, e016119, 2020.

DYKOVÁ, I.; AVILA, E. J. F.; FIALA, I. Kudoa dianae sp. n. (Myxosporea: Multivalvulida), a new parasite of bulls- eye puffer, Sphoeroides annulatus (Tetraodontiformes: Tetraodontidae). Folia Parasitologica, v. 49, p. 17-23, 2002.

EDUARDO, M. B. P.; SAMPAIO, J. L. M.; GONÇALVES, E. M. N.; CASTILHO, V. L. P.; RANDI, A. P.; THIAGO, C.; PIMENTEL, E. P.; PAVANELli, E. I.; COLlEONE, R. P.; Vigilato, M. A. N.; MARSigliA, D. A. P.; ATUI, M. B.; TORRES, D. M. A. G. V. Diphyllobothrium spp.: um Parasita Emergente em São Paulo, Associado ao Consumo de Peixe Cru - Sushis e Sashimis, São Paulo, Março de 2005. Boletim Epidemiológico Paulista, Ano 2, n. 15, 2005.

EIRAS, J. C. ; TAKEMOTO, R. M. ; PAVANELLI, G. C. Diversidade dos parasitas de peixes de água doce do Brasil. 1. ed. Maringá: Clichetec, 2010. Vol. 1. 333p.

FAJER-ÁVILA, E. J.; GUZMAN-BELTRAN, L.; ZÁRATE-RODRÍGUEZ, W. C.; DEL RÍO-ZARAGOZA, O. B.; ALMAZAN-RUEDA, P. Pathology caused by adult Pseudochondracanthus diceraus (Copepoda: Chondracanthidae), a parasite of bullseye puffer fish Sphoeroides annulatus. Revista de Biología Marina y Oceanografía, v. 46, n. 3, p. 293302, 2011.

FREDENSBORG, B. L.; LONGORIA, A. N. Increased Surfacing Behavior In Longnose Killifish Infected by Brain-Encysting Trematode. Journal of Parasitology, v. 98, n. 5, p. 899-903, 2012.

FROESE, R.; PAULY, D. Editors. FishBase. World Wide Web electronic publication. 2019. Disponível em: <www.fishbase.org, version > (12/2019). Acesso em 12 de out. De 2020. 
GIÃO, T.; PELEGRINI, L. S.; AZEVEDO, R. K.; ABDALLAH, V. D. Biodiversity of parasites found in the trahira, Hoplias malabaricus (Bloch, 1794), collected in the Batalha River, Tietê- Batalha drainage basin, SP, Brazil. In: Anais da Academia Brasileira de Ciências, v. 92, n. 2, 2020.

GIBSON D. I.; JONES, A.; BRAY, R. A. (Eds.). Keys to Trematoda. Vol. 1. Londres: CABI Publishing Wallingford, UK \& The Natural History Museum, 2002. 544 p.

GUERETZ, J. S.; MOURA, A. B.; MARTINS, M. L.; SOUZA, A. P. Estudo da prevalência de Ascocotyle (phagicola) longa em mugilídeos capturados na baía da Babitonga, Santa Catarina, Brasil. Archives of Veterinary Science, v. 24, n. 3, p. 79-87, 2019.

GUERETZ, J. S.; SENGER, S. B.; CLAUS, M. P. Ocorrência de Ithyoclinostomum sp. e Eustrongylides sp., parasitos de Hoplias aff. malabaricus Bloch, 1794 (Characiformes: Erythrinidae), no litoral de Santa Catarina, Brasil. Brazilian Journal of Development, v. 6, n. 4, p. 21565-21575, 2020.

GÜlliCH, R. I. C. Reflexões acerca da Etnobiologia e Etnoecologia no Brasil. Ponta Grossa: Atena Editora, 2019.

GURGEL-GONÇALVES, R.; MINUZZI-SOUZA, T. T. C.; COSTA-NETO, E. M.; CUBA, C. A. C. O que é um parasito? Uma análise etimológica e semântica do termo parasito em diferentes idiomas. Acta Scientiarum - Human and Social Sciences, v. 29, n. 2, p. 151-161, 2007.

HATJE, V.; ANDRADE, J. B. 2009. Baía de Todos os Santos: aspectos oceanográficos (org.) - Salvador: edUFBa, 306 p.:il.

HAVERROTH, M. Ensino e pesquisa em etnoecologia e etnobiologia na região Norte do Brasil. Ethnoscientia, v. 3, n. 2, 2018.

HAYS, T. E. An empirical method for the identification of covert categories in ethnobiology. American Ethnologist, v. 3, n. 3, p. 489-507, 1976.

HECHT, L. B. B.; THOMPSON, P. C.; ROSENTHAL, B. M. Assessing the evolutionary persistence of ecological relationships: A review and preview. Infection, Genetics and Evolution, v. 84, p. 1-7, 2020.

HERBST, D. F.; HANAZAKI, N. Local ecological knowledge of fishers about the life cycle and temporal patterns in the migration of mullet (Mugil liza) in Southern Brazil. Neotropical Ichthyology, v. 12, n. 4, p. 879-890, 2014.

IBAMA - INSTITUTO BRASILEIRO DO MEIO AMBIENTE E DOS RECURSOS NATURAIS RENOVÁVEIS. Boletim estatístico de pesca e aquicultura. 2011. Disponível em

$<$ https://www.icmbio.gov.br/cepsul/images/stories/biblioteca/download/estatistica/est_2011_b ol_bra.pdf $>$. Acesso em: 06 de out. de 2020. 
Dantas et al. Conhecimento tradicional dos pescadores artesanais sobre os parasitos de peixes do rio Jaguaripe, Bahia, nordeste do Brasil. Ethnoscientia V.6, n.1, 2021. DOI: 10.22276/ethnoscientia.v6i1.339

IBGE - Instituto Brasileiro de Geografia e Estatística. 2017. Disponível em: < http://ibge.gov.br/cidadesat/painel/painel.php?lang=\&codmun=292250\&search=bahia|nazare| infograficos:-dados-gerais-do-municipio>. Acesso em: 18 de outubro de 2017.

ISAAC, A.; GUIDELli, G. M.; FRANÇA, J. G.; PAVANELlI, G. C. Composição e estrutura das infracomunidades endoparasitárias de Gymnotus spp.(Pisces: Gymnotidae) do rio Baía, Mato Grosso do Sul, Brasil. Acta Scientiarum. Biological Sciences, v. 26, n. 4, p. 453-462, 2004.

LESTER, R. J. G.; HAYWARD, C. J. Phylum Arthropoda. In: WOO, P. T. K. (Ed.) Fish Diseases and Disorders, Wallingford: CABI, 2006, v. 1, p. 466-565.

LEWINSOHN, T. M.; FREITAS, A. V. L.; PRADO, P. I. Conservação de invertebrados terrestres e seus habitats no Brasil. Megadiversidade, v. 1, n. 1, p. 62-69, 2005.

LIMA, F. S.; CASALI, G. P.; TAKEMOTO, R. M. Crustacea. In: PAVANELLI, G. C.; TAKEMOTO, R. M.; EIRAS, J. C. (Org). Parasitologia de peixes de água doce do Brasil. Maringá: EDUEM, 2013. p. 371- 397.

LIMA, J. S.; ZAPPES, C. A.; DI BENEDITTO, A. P. M.; ZALMON, I. R. Ethnoecology and socioeconomic around an artificial reef: the case of artisanal fisheries from southeastern Brazil. Biota Neotropica, v. 19, n. 2, e20180620, 2019.

LOPES, P. R. D.; OLIVEIRA-SILVA, J. T.; FERREIRA-MELO, A. S. A. Contribuição ao conhecimento da ictiofauna do manguezal de Cacha Pregos, Ilha de Itaparica, Baía de Todos os Santos, Bahia. Revista brasileira de Zoologia, v. 15, n. 2, p. 315 - 325, 1998.

LUQUE, J. L. Parasitos: ¿Componentes ocultos de la Biodiversidad? Parasites: A hidden component of the Biodiversity? Biologist, v. 6, n. 1, p. 5-7, 2008.

LUQUE, J. L.; AGUIAR, J. C.; VIEIRA, F. M.; GIBSON, D. I.; SANTOS, C. P. Checklist of Nematoda associated with the fishes of Brazil. Zootaxa, v. 3082, p. 1-88, 2011.

LUQUE, J. L.; POULIN. R. Metazoan parasite species richness in Neotropical fishes: hotspots and the geography of biodiversity. Parasitology, v. 134, p. 865-878, 2007.

LUQUE, J. L.; TAVARES, L. E. R. Checklist of Copepoda associated with fishes from Brazil, Zootaxa, v. 1579, p. 1-39, 2007.

LUQUE, J. L.; VIEIRA, F. M.; TAKEMOTO, R. M.; PAVANELLI, G. C.; EIRAS, J. C. Checklist of Crustacea parasitizing fishes from Brazil. Check List, v. 9, n. 6, p. 1449-1470, 2013.

LYMBERY, A. J.; CHEAH, F. Y. Anisakid nematodes and anisakiasis. In: MURRELL, K. D.; FRIED, B. (Eds.). Food-Borne parasitic zoonoses: fish and Plant-Borne parasites. New York: Springer, 2007. v. 11. p. 185-207.

MARCOGLIESE, D. Food webs and the transmission of parasites to marine fish. Parasitology, v. 124, p. S83-S99, 2002. 
MARQUES, J. G. W. Etnoictiologia: pescando pescadores nas águas da transdisciplinaridade. Revista Ouricuri, v. 2, n. 2, p. 9-36, 2012.

MARQUES, J. G. W. O olhar (des)multiplicado. O papel do interdisciplinar e do qualitativo na pesquisa etnobiológica e etnoecológica. In: AMOROZO, M. C. M.; MINGG, L. C.; SILVA, S. M. P. (Ed.). Métodos de coleta e análise de dados em etnobiologia, etnoecologia e disciplinas correlatas. Rio Claro: UNESP/CNPq, 2002. p. 31-46.

MARTÍNEZ-AQUINO, A.; GARCÍA-TEH, J. G.; CECCARELLI, F. S.; AGUILARAGUILAR, R.; VIDAL-MARTÍNEZ, V. M.; AGUIRRE-MACEDO, M. L. New morphological and molecular data for Xystretrum solidum (Gorgoderidae, Gorgoderinae) from Sphoeroides testudineus (Tetraodontiformes, Tetraodontidae) in Mexican waters. Zookeys, v. 925, p. 141-161, 2020.

MEDEIROS, P. M.; ALMEIDA, A. L. S.; LUCENA, R. F. P.; SOUTO, F. J. B.; ALBUQUERQUE, U. P. Use of Visual Stimuli in Ethnobiological Research. In: ALBUQUERQUE, U. P.; CUNHA, L. V. F. C.; LUCENA, R. F. P.; ALVES, R. R. N. (Eds.). Methods and Techniques in Ethnobiology and Ethnoecology. Nova Iorque: Springer. 2014. p. 87-98.

MEJÍA-MADRID, H. H.; AGUIRRE-MACEDO, M. L. Redescription and Genetic Characterization of Cucullanus dodsworthi (Nematoda: Cucullanidae) from the checkered puffer Sphoeroides testudineus (Pisces: Tetraodontiformes). Journal of Parasitology, v. 97, n. 4, p. 695-706, 2011.

MESSIAS, M.; ALVES, T.; MELO, C.; LIMA, M.; RIVERA-REBELLA, C.; RODRIGUES, D.; RISCALA MADI, R. 2019. Ethnoecology of Lutjanidae (snappers) in communities of artisanal fisheries in northeast Brazil. Ocean \& Coastal Management, v. 181, 2019.

MINISTÉRIO DA SAÚDE, FUNDAÇÃO NACIONAL DE SAÚDE. Manual de diagnóstico e tratamento de acidentes por animais peçonhentos. $2^{\mathrm{a}}$ ed. - Brasília: Fundação Nacional de Saúde, 2001. 120 p.

MOLNÁR, K.; BUCHMANN, K.; SZÉKELY, C. Phylum Nematoda. In: WOO (ed.) Fish Diseases and Disorders. Volume 1: Protozoan and Metazoan Infections. Wallingford: CABI, p. 417- 443, 2006.

MORALES-SERNA, F. N.; MEDINA-GUERRERO, R. M.; FAJER-AVILA, E. J. Sea lice (Copepoda: Caligidae) parasitic on fishes reported from the Neotropical region. Neotropical Biodiversity, v. 2, n. 1, p. 141-150, 2016

MORAVEC, F.; MONTOYA-MENDOZA, J.; SALGADO-MALDONADO, G. A new genus and species of philometrid (Nematoda) from the subcutaneous tissue of the crevalle jack, Caranx hippos (Osteichthyes), from the Southern Gulf of Mexico. Journal of Parasitology, v. 94, n. 6, p. 1346-1350, 2008. 
MOURA, F. B. P.; MARQUES, J. G.W. Conhecimento de pescadores tradicionais sobre a dinâmica espaço-temporal de recursos naturais na Chapada Diamantina, Bahia. Biota Neotropica, v.7, n.3, p. 119-126, 2006.

NEGREIROS, L. P.; FLORENTINO, A. C.; PEREIRA, F. B.; TAVARES-DIAS, M. Longterm temporal variation in the parasite community structure of metazoans of Pimelodus blochii (Pimelodidae), a catfish from the Brazilian Amazon. Parasitology Research, v. 118, p. 3337-3347, 2019.

NUNES, A. C. F.; SÁ, V. J.; LIMA, M. M. O termo zoonoses na concepção dos moradores do bairro Multirão, localizado no município de Serra Talhada/PE. In: SEABRA, G.; MENDONÇA, I. (Orgs.). Educação ambiental: Responsabilidade para a conservação da sociobiodiversidade. João Pessoa: Editora Universitária da UFPB, 2011a, p. 24-28.

NUNES, D. M.; HARTZ, S.M.; SILVANO, R.A. M. Conhecimento ecológico local e científico sobre os peixes na pesca artesanal no Sul do Brasil. Boletim do Instituto de Pesca. v. 37, n. 3, 2011b, p. $209-223$.

PAPERNA, I.; DZIKOWSKI, R. Digenea (Phylum Platyhelminthes). In: WOO (ed.) Fish Diseases and Disorders. Volume 1: Protozoan and Metazoan Infections. Wallingford: CABI, 2006, p. 345-390.

PAVANELLI, G. C.; EIRAS, J. C.; YAMAGUCHI, M. U.; TAKEMOTO, R. M. Zoonoses humanas transmissíveis por peixes no Brasil. 1. Ed. Maringá: Unicesumar, 2015. v. 1. 145 p.

PAVAnelli, G. C.; TAKEMOTO, R. M.; EIRAS, J. C. (Org). Parasitologia de peixes de água doce do Brasil. Maringá: Eduem, 2013, 452 p.

PIEVE, S. M. N.; KUBO, R. R.; COELHO-DE-SOUZA, G. Pescadores da Lagoa Mirim Etnoecologia e Resiliência. Brasília: Ministério do Desenvolvimento Agrário. 2009. 244p.

POULIN, R. Evolutionary Ecology of Parasites: (Second Edition). (2 ${ }^{\mathrm{a}}$ Ed., Course Book ed.). Princeton: Princeton University Press. 2011.

PRADO, H. M.; MURRIETA, R. S. S. A etnoecologia em perspectiva: origens, interfaces e correntes atuais de um campo em ascensão. Ambiente \& Sociedade, v. 18, n. 4, p. 139-160, 2015.

PRESTON, D. L.; MISCHLER, J. A.; TOWNSEND, A. R.; JOHNSON, P. T. J. Disease Ecology Meets Ecosystem Science, Ecosystems, v. 19, p. 737-748, 2016.

PROKOP, P., \& FANČOVIČOVÁ, J. The association between disgust, danger and fear of macroparasites and human behaviour. Acta Ethologica, v. 13, n. 1, p. 57-62, 2010.

PUGAS, R. M.; MATEUS, GUSTAVO A. P. A pesca sustentável em Maragogipinho, Aratuípe, Bahia, Brasil. Revista UNINGÁ, v. 26, n. 1, p. 36-41, 2016

RAMESHKUMAR, G.; RAVICHANDRAN, S. Cymothoa indica (Isopoda; Cymothoidae) 
and Alitropus typus (Isopoda; Aegidae) on freshwater fish Tilapia mossambica (Cichlidae) in Vellar estuary, Southeast coast of India. Biotemas, v. 23, n. 3, p. 67-70, 2010.

RESENDE, E. K.; PEREIRA, R. A. C.; SÓRIO, V. F.; GALVÃO, E. M. Biologia da Tuvira, Gymnotus cf. carapo (Pisces, Gymnotidae) no Baixo Rio Negro, Pantanal, Mato Grosso do Sul, Brasil. Corumbá: Embrapa Pantanal, 42 p., 2006.

ROCHA, C.; FAVARO, L. F.; SPACH, H. L. Biologia reprodutiva de Sphoeroides testudineus (Linnaeus) (Pisces, Osteichthyes, Tetraodontidae) da Gamboa do Baguaçu, Baía de Paranaguá, Paraná, Brasil. Revista Brasileira de Zoologia, v. 19, n. 1, p. 57-63, 2002.

ROCHA, C. F. D.; BERGALlO, H. G.; BITTENCOURT, E. B. More than just invisible inhabitants: parasites are important but neglected components of the biodiversity. Zoologia, v. 33, n. 3, e20150198, 2016.

ROSA, M.; OREY, D. C. Interlocuções polissêmicas entre a etnomatemática e os distintos campos de conhecimento etno-X. Educação em Revista, v. 30, n. 3, p. 63-97, 2014.

RUPPERT, E.E., FOX, R.S. \& BARNES, R.D. Zoologia dos Invertebrados. $7^{\text {a }}$ ed., São Paulo: Roca, 2005, 1145 p.

SANTOS, C. P.; BORGES, J. N.; FERNANDES, E. S.; PIZANI, A. P. C. L. 2013. Nematoda. In: PAVANELli, G. C.; TAKEMOTO, R. M.; EIRAS, J. C. (Org). Parasitologia de peixes de água doce do Brasil. Maringá: EDUEM, 2013. p. 333-352.

SANTOS-LIMA, T. M.; SANTOS, D. R. V.; SOUZA, R. M.; BASTOS, N. G.; VANNIERSANTOS, M. A.; NUNES, E. S.; DIAS-LIMA, A. G. Plantas medicinais com ação antiparasitária: conhecimento tradicional na etnia Kantaruré, aldeia Baixa das Pedras, Bahia, Brasil. Revista Brasileira de Plantas Medicinais, v. 18, n. 1, supl. I, p. 240-247, 2016.

SCHOLZ, T.; AGUIRRE-MACEDO, M. L.; SALGADO-MALDONADO, G. Trematodes of the family Heterophyidae (Digenea) in Mexico: a review of species and new host and geographical records. Journal of Natural History, v. 35, n. 12, p. 1733-1772, 2001.

SILVA, A. I. F.; CANTANHEDE, S. P. D.; SOUSA, J. O.; LIMA, R. M.; SILVA-SOUZA, N.; CARVALHO-NETA, R. N. F.; ALMEIDA, Z. S.; SANTOS, D. M. S.; CARVALHO NETA, A. V.; SERRA, I. M. R. S.; TCHAICKA, L. Community Perceptions on Schistosomiasis in Northeast Brazil. The American Journal of Tropical Medicine and Hygiene, v. 103, n. 3, p. 1111-1117, 2020.

SILVANO, R. A. M.; BEGOSSI, A. Fishermen's local ecological knowledge on Southeastern Brazilian coastal fishes: contributions to research, conservation, and management. Neotropical Ichthyology, v. 10, n. 1, p. 133-147, 2012.

SMIT, N. J.; BRUCE, N. L.; HADFIELD, K. A. Global diversity of fish parasitic isopod crustaceans of the family Cymothoidae. International Journal for Parasitology, v. 3, p. 188-197, 2014. 
SOUTO, W. M. S.; BARBOZA, R. R. D.; ROCHA, M. S. P.; ALVES, R. R. N.; MOURÃO, J. S. Animal-based medicines used in ethnoveterinary practices in the semi-arid region of Northeastern Brazil. Anais da Academia Brasileira de Ciências, v. 84, n. 3, p. 669-678, 2012.

SOUZA, N. S.1, COSTA NETO, E. M.2, GURGEL-GONÇALVES, R. Os barbeiros e a doença de chagas segundo os moradores da zona rural do município de Tremedal, Sudoeste da Bahia: uma abordagem etnoparasitológica. In: SEABRA, G.; MENDONÇA, I. (Orgs.). Educação ambiental: Responsabilidade para a conservação da sociobiodiversidade. João Pessoa: Editora Universitária da UFPB, p. 119-125, 2011.

TAKEMOTO, R.; LIZAMA, M.; GUIDELLI, G.; PAVANELLI, G. Parasitos de peixes de aguas continentais. In: RANZANI-PAIVA, M. J. T.; TAKEMOTO, R. M.; PEREZ LIZAMA, M. A. (Orgs.). Sanidade de organismos aquáticos. São Paulo: Livraria Varela, p. 179-198, 2004.

TAVARES-DIAS, M.; MARTINS, M.L. An overall estimation of losses caused by diseases in the Brazilian fish farms. Journal of Parasitic Diseases, v.41, n.5, p.913-918, 2017.

THATCHER, V. E. Brasacanthus sphoeroides gen. n., sp. n. (Acanthocephala, Echinorhynchidae) from a coastal marine fish of Paraná State, Brazil. Revista Brasileira de Zoologia, v. 18, n. 4, p.1319-1323, 2001.

TOKŞEN, E.; NEMLİ, E.; DEĞİRMENCİ, U. The morphology of Lernanthropus kroyeri van Beneden, 1851 (Copepoda: Lernanthropidae) parasitic on sea bass, Dicentrarchus labrax (L., 1758), from the Aegean Sea, Turkey. Türkiye Parazitoloji Dergisi, v. 32, n. 4, p. 386 - 389, 2008.

TOMCHINSKY, E.; BARROS, F. B.; CORONA-M, E.; MING, L. C.; WELCH, J. R. Publicações científicas das etnociências: caminhos passados e futuros. Ethnoscientia, v. 4, p. 1-16, 2019.

VASCO-DOS-SANTOS, D. R.; SANTOS, J. V.; ANDRADE, W. M.; SANTOS-LIMA, T. M.; LIMA, L. N.; DIAS-LIMA, A. G.; ANDRADE, M. J. G.; VANNIER-SANTOS, M. A.; MOURÃO, G. J. B.; NUNES, E. S. Antiparasitic plants used by the Kantaruré-batida indigenous community (NE-Brazil): ethnobotany and local knowledge-erosion risks. Ambiente \& Sociedade, v. 21, 2018.

VENTURA, A. S.; PÁDUA, S. B.; ISHIKAWA, M. M.; MARTINS, M. L.; TAKEMOTO, R. M.; JERÔNIMO, G. T. Endoparasites of Gymnotus sp. (Gymnotiformes: Gymnotidae) from commercial baitfish farming in Pantanal Basin, Central Brazil. Boletim do Instituto de Pesca, v. 44, n. 3, e322, 2018.

VÍCTORA, C. G.; KNAUTH, D. R.; HASSEN, M. N. A. Pesquisa qualitativa em saúde uma introdução ao tema. Porto Alegre: Tomo Editorial, 2000. 133 p.

VIDAL-MARTÍNEZ, V. M.; MENDOZA-FRANCO, E. F. Heterobothrium lamothei n. sp. (Monogenea: Diclidophoridae) from the gills of Sphoeroides testudineus (Pisces: Tetraodontidae) from the coast of Yucatán, Mexico. Revista Mexicana de Biodiversidad, v. 
79, p. 89S- 93S, 2008.

VIERTLER, R. B. 2002. Métodos antropológicos como ferramenta para estudos em etnobiologia e etnoecologia. In: AMOROZO, M. C. M.; MING, L. C.; SILVA, S. M. P. (Eds). Métodos de Coleta e Análise de Dados em Etnobiologia, Etnoecologia e Disciplinas Correlatas. Rio Claro: UNESP/CNPq, 2002. p. 11-29.

WILLIAMS, M.; HERNANDEZ-JOVER, M.; SHAMSI, S. Fish substitutions which may increase human health risks from zoonotic seafood borne parasites: a review. Food Control, v. $118,2020$.

WOO, P. T. K. (Ed.) Fish Diseases and Disorders, Wallingford: CABI, 2006, v. 1, 791 p. 